
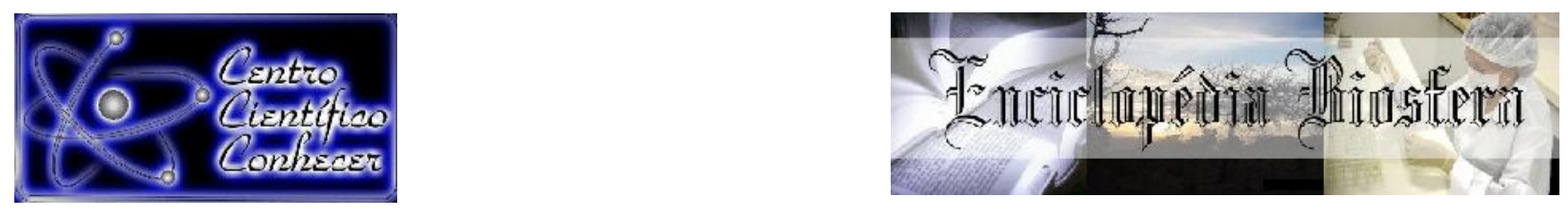

\title{
QUALIDADE DE LEITE CRU REFRIGERADO OBTIDO DE ORDENHA MANUAL E MECANIZADA PRODUZIDO NO MUNICÍPIO DE PORTO ACRE, AMAZÔNIA OCIDENTAL
}

Laryssa Oliveira de Araújo ${ }^{1}$, Marília Temporim Furtado², Nayane Cunha da Silva ${ }^{3}$

1Engenheira Agrônoma pela Universidade Federal do Acre (UFAC),

Rio Branco-AC, Brasil.

E-mail: engeagrolary@gmail.com

2Mestre em Agronomia pela Universidade Federal do Acre (UFAC), Rio

Branco-AC, Brasil

${ }^{3}$ Engenheira Agrônoma, pela Universidade Federal do Acre (UFAC),

Rio Branco-AC, Brasil

Recebido em: 06/04/2019 - Aprovado em: 10/06/2019 - Publicado em: 30/06/2019

DOI: 10.18677/EnciBio_2019A113

\begin{abstract}
RESUMO
Este trabalho teve por objetivo verificar se a qualidade do leite cru refrigerado obtido de ordenha manual e mecanizada em cinco propriedades rurais do município de Porto Acre, estão em conformidade com a Instrução Normativa nº 62/2011, para o consumo humano. Análises físico-químicas foram realizadas segundo metodologia do Instituto Adolf Lutz, determinando valores de acidez em ácido lático, gordura total, proteína total, extrato seco desengordurado e crioscopia, além das microbiológicas, em relação ao tipo de ordenha. $O$ delineamento experimental empregado foi o inteiramente casualizado, composto de cinco tratamentos (propriedades rurais) e quatro repetições. As amostras de leite obtidas em todas as propriedades estão de acordo com a legislação em relação a acidez, gordura e a proteína. A presença de coliformes termotolerantes se mostrou elevada em três propriedades, no entanto, os valores reduziram no decorrer das coletas. A contagem bacteriana total em todas as propriedades apresentou valores de acordo com a legislação vigente, isto é, abaixo do máximo estabelecido. Os resultados obtidos mostraram que no início da coleta das amostras do leite, não eram aplicadas medidas higiênicas adequadas e que com o passar das semanas, os produtores melhoraram o manejo na ordenha reduzindo a contaminação do leite.
\end{abstract}

PALAVRAS-CHAVE: boas práticas de fabricação, qualidade do leite, segurança alimentar. 


\title{
QUALITY OF REFRIGERATED RAW MILK OBTAINED FROM MANUAL AND MECHANIZED MILKING PRODUCED IN THE COUNTY OF PORTO ACRE, WESTERN AMAZON
}

\begin{abstract}
The objective of this study was to verify if the quality of refrigerated raw milk obtained from manual and mechanized milking in five rural properties in the city of Porto Acre is in accordance with Normative Instruction No. 62/2011 for human consumption. Physical-chemical analyzes were performed according to the methodology of the Adolf Lutz Institute, determining acidity values in lactic acid, total fat, total protein, dry extract, and cryoscopy, besides the microbiological ones, in relation to the type of milking. The experimental design was the completely randomized, composed of five treatments (rural properties) and four replications. Milk samples obtained at all properties are in accordance with the legislation in relation to acidity, fat and protein. The presence of thermotolerant coliforms was high in three properties, however, the values decreased during the collections. The total bacterial count in all properties presented values according to the current legislation, that is, below the established maximum. The results showed that at the beginning of the collection of the milk samples, adequate hygienic measures were not applied and that with the passage of the weeks, the producers improved the management in the milking reducing milk contamination.
\end{abstract}

KEYWORDS: good manufacturing practices, milk quality, food security.

\section{INTRODUÇÃO}

De acordo com a FAO (2017), o Brasil encontra-se entre os países que possuem maior produção de leite do mundo, ocupando a quarta posição no "ranking mundial". Contudo, essa produção vem acompanhada de muitos desafios e dificuldades, como a má qualidade do produto final e a condição sanitária dos estabelecimentos e equipamentos utilizados na ordenha (MOURA et al., 2017).

O leite é produto de vacas sadias e bem alimentadas, apresentado em forma líquida e de cor branca opaca, viscoso, com maior densidade que a água. Possui alto valor biológico, é fonte de vários nutrientes, como proteínas, açúcares, lipídeos, vitaminas e sais minerais, sendo considerado um dos alimentos mais completos para os seres humanos (JOSÉ NETO et al., 2014).

O controle da qualidade do leite consumido pela população brasileira torna-se importante, tendo em vista, que o mesmo apresenta alta perecibilidade, com condições propícias de deterioração, podendo ser avaliadas por parâmetros físicoquímicos como acidez titulável, densidade e índice crioscópico; padrões higiênicosanitários como contagem bacteriana, células somáticas e resíduos de antibióticos; e medidas de composição, como gordura, extrato seco e proteínas (ROCHA et al., 2016). Dessa forma, a obtenção adequada do produto em termos de segurança alimentar, depende de um processo de produção monitorado, incluindo desde o manejo do rebanho, ordenha, até a chegada à mesa do consumidor (DIAS; ANTES, 2014).

Produzir leite de qualidade oferece diversos benefícios, dentre eles, melhor remuneração aos produtores, maior segurança alimentar, menor custo de produção e satisfação dos consumidores que estão cada vez mais exigentes, além de 
contribuir para as indústrias comercializarem seus produtos dentro da norma estabelecida pela legislação brasileira (PAULA et al., 2010).

Levando em consideração a importância do leite na alimentação humana, e a condição higiênica do manuseio, objetivou-se com este trabalho, verificar se a qualidade microbiológica e físico-química do leite cru refrigerado obtido de ordenha manual e mecanizada, proveniente de cinco propriedades rurais do município de Porto Acre, estão em conformidade com a Instrução Normativa no 62/2011 (BRASIL, 2011), que normatiza o padrão de identidade e qualidade para este tipo de alimento.

\section{MATERIAL E MÉTODOS}

O presente trabalho foi realizado na Unidade de Tecnologia de Alimentos UTAL, localizada na Universidade Federal do Acre. Amostras de leite cru refrigerado de cinco propriedades rurais localizadas no município de Porto Acre, Amazônia Ocidental, Brasil, foram coletadas nos meses de agosto e setembro de 2018, durante quatro semanas, transportadas assepticamente em frascos esterilizados, em caixa de material isotérmico, com barras de gelo e levadas para o laboratório da UTAL.

As cinco propriedades foram classificadas quanto ao tipo de ordenha, sendo as P1, P2, P3 e P4 manual e P5 mecanizada. Análises microbiológicas foram realizadas como um dos parâmetros para verificação da qualidade das amostras de leite e consistiram na detecção de coliformes termotolerantes a $45^{\circ} \mathrm{C}$ e contagem bacteriana total.

Para a análise microbiológica de coliformes termotolerantes a $45{ }^{\circ} \mathrm{C}$ foi utilizada a metodologia descrita por Silva et al. (2017), em que $25 \mathrm{~mL}$ de cada amostra de leite foi adicionada em $225 \mathrm{~mL}$ de solução salina ou água peptonada $0,1 \%$, para posterior realização da diluição $10^{-1}$, de onde foi transferido $1 \mathrm{~mL}$ para um tubo contendo $9 \mathrm{~mL}$ de água peptonada para formação da diluição $10^{-2}$, da qual foi transferido $1 \mathrm{~mL}$ para outro tubo contendo $9 \mathrm{~mL}$ de solução salina, formando a diluição $10^{-3}$.

Posterior a isso, foi realizado o teste presuntivo, em que $1 \mathrm{~mL}$ de cada uma das três diluições foi inoculado em uma série de três tubos pequenos, contendo 10 $\mathrm{mL}$ de lactose, em seguida, os tubos foram para a incubadora a $35^{\circ} \mathrm{C}$ por 48 horas. Para a confirmação final da presença ou ausência de coliformes termotolerantes dos tubos que apresentaram resultados positivos, ou seja, com a fermentação e presença de gás no tubo Duhran, foi transferido, com ajuda de palitos esterilizados, amostras dos tratamentos positivos para tubos menores com meio com Escherichia coli que ficaram em banho maria, $45^{\circ} \mathrm{C}$ por 24 horas.

Para realização da contagem bacteriana total, foram separadas placas contendo o meio de lactose, devidamente identificadas com as diluições $10^{-1}, 10^{-2} \mathrm{e}$ $10^{-3}$ para cada tratamento, em que foi inoculado $1 \mathrm{~mL}$ de cada diluição nas placas, que em seguida, foram para a incubadora a $35^{\circ} \mathrm{C}$, por um período de 48 horas, onde foi feita a contagem das colônias em placas.

A avaliação físico-química realizada, consistiu na identificação da acidez em ácido láctico, extrato seco desengordurado, teor de gordura e proteína e índice crioscópico do leite. Todas as amostras foram analisadas em duplicata, seguindo a metodologia do Instituto Adolf Lutz (IAL, 2008). 
Foram pipetados $10 \mathrm{~mL}$ das cinco amostras (duplicata) em Erlenmeyer de 125 $\mathrm{mL}$, posteriormente, adicionadas 5 gotas de solução de fenolftaleína para titulação com solução de hidróxido de sódio $0,1 \mathrm{M}$, até aparecimento de uma coloração rósea, para determinação da acidez em ácido láctico.

O extrato seco total foi feito apenas para determinação do extrato seco desengordurado, em que foram transferidos $10 \mathrm{~mL}$ das amostras para Becker de 50 $\mathrm{mL}$ com as massas previamente mensuradas, posteriormente, secadas em estufa a $105^{\circ} \mathrm{C}$ por 24 horas e resfriadas em dessecador para pesagem final. Posterior a isso, o extrato seco desengordurado foi obtido pela diferença entre o extrato seco total e o teor de gordura de cada amostra.

Para determinação do teor de gordura do leite foi utilizado o método de Gerber, mediante o uso de butirômetros, nos quais foram adicionados $10 \mathrm{~mL}$ de ácido sulfúrico específico para análise de leite, com densidade de 1,820 a 1,825 $\mathrm{g} / \mathrm{cm}^{3}, 11 \mathrm{~mL}$ de cada amostra para o interior do butirômetro e $1,5 \mathrm{~mL}$ de álcool isoamílico normal, densidade $0,815 \mathrm{~g} / \mathrm{cm}^{3}$. Em seguida, a amostra foi centrifugada por 5 minutos a 1000-1200 rpm e permaneceram no banho-maria a $65^{\circ} \mathrm{C}$ durante 5 minutos para leitura final da porcentagem de gordura das amostras com base no menisco formado pela camada de gordura.

O teor de proteína foi determinado pelo método de tubos de Kjeldahl, nos quais foram adicionados $1,5 \mathrm{~mL}$ das amostras, $2 \mathrm{~g}$ de mistura catalítica e $7,5 \mathrm{~mL}$ de ácido sulfúrico. Posteriormente foi realizado o processo de digestão por aquecimento durante 4 horas. Na sequência, adicionou-se $20 \mathrm{~mL}$ de ácido bórico e 5 gotas de azul de metileno que passaram pelo Destilador de Nitrogênio juntamente com o tubo de Kjedahl correspondente a cada tratamento para posterior titulação com ácido clorídrico.

O índice crioscópico ou ponto de congelamento do leite juntamente com a porcentagem de água adicionada, foi determinado mediante uso do equipamento Eletrônico MicroLak - Entelbra, em que foi feita a leitura de $2 \mathrm{~mL}$ de cada amostra de leite em duplicata.

Os resultados das análises foram comparados com a legislação brasileira vigente, segundo valores da Instrução Normativa no 62 de 29 de dezembro de 2011, do Ministério da Agricultura, Pecuária e Abastecimento (BRASIL, 2011).

Para fins de análise estatística utilizou-se 0 delineamento experimental inteiramente casualizado (DIC), considerando cinco tratamentos, P1, P2, P3, P4 e $\mathrm{P} 5$, ou seja, cada propriedade foi considerada como um tratamento, com quatro repetições, totalizando vinte parcelas experimentais.

Os dados obtidos foram submetidos à análise de variância com auxílio do software Sisvar, sendo as médias dos diferentes tratamentos comparadas pelo teste de Tukey, ao nível de $5 \%$ de probabilidade.

\section{RESULTADOS E DISCUSSÃO}

As amostras de leite cru refrigerado avaliadas estão em conformidade com os padrões exigidos pela legislação brasileira, somente nos parâmetros de acidez titulável, gordura e proteína, além dos parâmetros microbiológicos. 


\section{Parâmetros físico-químicos}

Os parâmetros físico-químicos das amostras analisadas de leite cru obtido por ordenha manual e mecanizada os valores estão descritos na Tabela 1.

TABELA 1- Valores médios da composição físico-química das amostras de leite cru refrigerado, obtido por ordenha manual e mecânica.

\begin{tabular}{ccccccc}
\hline \multirow{2}{*}{ Variáveis } & \multicolumn{5}{c}{ Propriedades rurais } & \multirow{2}{*}{ CV (\%) } \\
\cline { 2 - 6 } & $\mathrm{P} 1$ & $\mathrm{P} 2$ & $\mathrm{P} 3$ & $\mathrm{P} 4$ & $\mathrm{P} 5$ & \\
Acidez $^{*}$ & $0,16 \mathrm{a}$ & $0,15 \mathrm{a}$ & $0,16 \mathrm{a}$ & $0,15 \mathrm{a}$ & $0,15 \mathrm{a}$ & 12,93 \\
Gordura* $^{*}$ & $3,53 \mathrm{ab}$ & $4,08 \mathrm{ab}$ & $4,28 \mathrm{ab}$ & $3,38 \mathrm{ab}$ & $3,05 \mathrm{a}$ & 13,49 \\
Proteína $^{*}$ & $3,14 \mathrm{a}$ & $3,27 \mathrm{a}$ & $3,46 \mathrm{a}$ & $3,09 \mathrm{a}$ & $3,30 \mathrm{a}$ & 1,15 \\
ESD $^{*}$ & $8,08 \mathrm{a}$ & $7,29 \mathrm{a}$ & $7,86 \mathrm{a}$ & $7,85 \mathrm{a}$ & $7,59 \mathrm{a}$ & 18,78 \\
Crioscopia $^{* *}$ & $-0,519 \mathrm{a}$ & $-0,515 \mathrm{a}$ & $-0,525 \mathrm{a}$ & $-0,521 \mathrm{a}$ & $-0,525 \mathrm{a}$ & 13,86 \\
Água (\%) & $2,09 \mathrm{a}$ & $2,90 \mathrm{a}$ & $1,27 \mathrm{a}$ & $1,76 \mathrm{a}$ & $1,27 \mathrm{a}$ & 19,93 \\
\hline
\end{tabular}

ESD-Extrato Seco Desengordurado; *expresso em g/100 mL; **expresso em ${ }^{\circ} \mathrm{H}$.

Médias seguidas de letras iguais na mesma linha não diferem entre si $(p>0,05)$ pelo teste $d$ Tukey a $5 \%$ de probabilidade.

A acidez titulável presente nas amostras das cinco propriedades estavam de acordo com valores estabelecidos na legislação brasileira para o consumo humano, que varia de 0,14 a $0,18 \mathrm{~g} / 100 \mathrm{~mL}$ de leite. Silva et al. (2010a) encontraram valores semelhantes $(0,16 \mathrm{~g} / 100 \mathrm{~mL})$ quando comparavam os tipos de ordenha manual e mecânica em propriedades leiteiras. Os mesmos valores variando entre 0,15 e 0,16 $\mathrm{g} / 100 \mathrm{~mL}$ foram encontrados por Paula et al. (2010) que avaliaram a qualidade do leite em diferentes meses do ano.

Como pode ser observado, conforme a legislação na Tabela 2 e os valores médios na Tabela 1, os teores de gordura verificados nas análises estão acima dos recomendados para o leite cru refrigerado, que pode significar aumento de fibra na alimentação dos animais (NEPUCENO, 2016), ou até mesmo a incidência de mastite no rebanho. Valores médios semelhantes, variando de 3,55 a 4,02 g/100 mL foram encontrados por Almeida et al. (2016) ao pesquisarem a adequação do leite cru à legislação vigente em municípios de Minas Gerais.

TABELA 2- Requisitos físico-químicos e microbiológicos do leite cru refrigerado, segundo a Instrução Normativa no 62.

\begin{tabular}{ll}
\hline Item de composição & Requisitos \\
\hline Acidez $(\mathrm{g} / 100 \mathrm{~mL})$ & $0,14-0,18$ \\
Gordura $(\mathrm{g} / 100 \mathrm{~mL})$ & Mín 3,0 \\
Proteína $(\mathrm{g} / 100 \mathrm{~mL})$ & Mín 2,9 \\
Extrato Seco Desengordurado $(\mathrm{g} / 100 \mathrm{~mL})$ & Mín 8,4 \\
Crioscopia $\left({ }^{\circ} \mathrm{H}\right)$ & $-0,530-0,550$ \\
Água $(\%)$ & 0,00 \\
CBT (UFC. $\left.\mathrm{mL}^{-1}\right)$ & $1,0 \times 10^{5}$ \\
\hline
\end{tabular}

Fonte: Brasil, 2011. 
No presente estudo, verificou-se que nas propriedades onde realizou-se a coleta de leite manualmente (P1, P2, P3 e P4), os teores de gordura se mostraram mais elevados em relação a P5, que fez a ordenha mecanizada. Os teores de proteína encontrados no leite analisado estiveram de acordo com o exigido pela legislação e foram semelhantes aos encontrados por Silva et al. (2010b), que obtiveram de 3,25 a 3,35 g/100 mL e Santos et al. (2008) com valores entre 3,22 e 3,25 g/100 mL, analisando amostras em tanques de expansão em diferentes períodos de armazenamento.

Santos et al. (2008) encontraram teores médios de ESD $(8,6 \mathrm{~g} / 100 \mathrm{~mL})$ dentro do recomendado pela legislação em leites armazenados em tanques de expansão, enquanto que no presente estudo, o leite não era armazenado e os valores se apresentaram abaixo do indicado pela legislação. Os baixos teores de ESD encontrados no leite do presente estudo, com valores inferiores ao mínimo exigido pela legislação, pode ser explicado pela época de coleta que foi realizada no período seco do ano, em que há déficit na alimentação dos animais leiteiros.

As amostras de leite provenientes das cinco propriedades leiteiras apresentaram alteração com adição de água, com a crioscopia variando de $-0,515$ a $-0,525^{\circ} \mathrm{H}$. Souza et al. (2014) encontraram valores superiores em seu trabalho variando de $-0,532 \stackrel{\circ}{\circ}$ a 0,559 으. Com o objetivo de aumentar o volume de produção, a água reduz o valor nutritivo do leite, além de prejudicar a qualidade microbiológica do produto, pois, não se sabe sua origem e a qualidade (LAMAS et al., 2016).

\section{Parâmetros microbiológicos}

Leites obtidos de maneira mecanizada, podem apresentar número mais reduzido de microrganismos, pois, ficam em tanques de resfriamento, enquanto a ordenha é realizada, e o leite obtido manualmente é deixado em baldes com temperatura ambiente no período da ordenha, só sendo levado para tanques de resfriamento ao final do processo, o que facilita a multiplicação de microrganismos mesófilos (MARTINS et al., 2012).

A Tabela 3 apresenta os resultados das análises microbiológicas, referentes à presença ou ausência de coliformes termotolerantes a $45^{\circ} \mathrm{C}$, das amostras de leite das cinco propriedades avaliadas neste estudo no decorrer das quatro coletas, sendo que esses microrganismos como Escherichia coli indicam contaminações de origem fecal.

TABELA 3- Coliformes termotolerantes a $45{ }^{\circ} \mathrm{C}$ das amostras de leite cru refrigerado no decorrer das quatro semanas de coleta.

\begin{tabular}{cccccc}
\hline \multirow{2}{*}{ Coleta } & \multicolumn{5}{c}{ Coliformes Termotolerantes a $\mathbf{4 5}$ ㅇ (NMP. $\mathbf{m L}^{-1}$ ) } \\
\cline { 2 - 6 } 1 & P1 & P2 & P3 & P4 & P5 \\
\cline { 2 - 6 } & 3,0 & $* *$ & 7,4 & $* *$ & 6,2 \\
3 & 7,4 & $* *$ & 7,4 & $* *$ & 3,6 \\
4 & $* *$ & $* *$ & $* *$ & $* *$ & 3,6 \\
\hline
\end{tabular}

Padrão Não estabelecido

** Ausente 
Apesar de não ter valores definidos pela legislação para coliformes termotolerantes em leite cru refrigerado, sua presença indica contaminação de origem fecal no produto. Mediante resultados de coliformes obtidos, verificou-se deficiência de condições higiênico-sanitárias na obtenção do leite, principalmente na P5, cuja ordenha é mecanizada, e apresentou valores entre 3,6 a 6,2 NMP. $\mathrm{mL}^{-1}$.

Em duas das propriedades, cuja obtenção do leite foi feita de maneira manual (P1 e P3), os valores se mostraram entre 3 e 7,4 NMP. $\mathrm{mL}^{-1}$ apenas na $1^{\text {a }}$ e $2^{\underline{a}}$ semanas de coleta, posteriormente, houve ausência dos coliformes (Tabela 3). Enquanto que as propriedades P2 e P4, demonstraram condições higiênicas adequadas durante a ordenha nas quatro semanas de coleta. $O$ que evidencia que independentemente do tipo de ordenha, é importante que se tenha cuidados higiênico-sanitários com uso das boas práticas.

$\mathrm{Na}$ ordenha mecanizada se não houver controle de higienização dos equipamentos, o leite obtido será mais contaminado do que na ordenha manual, tendo em vista que na mecânica, necessita de maiores técnicas de limpeza dos equipamentos. Porém, é indispensável o cuidado com a higiene nos dois tipos de ordenha.

Martins et al. (2012) encontraram no município de Frutal, MG, presença de coliformes termotolerantes em todas as amostras das propriedades com ordenha mecanizada, variando entre 930 e $1100 \mathrm{NMP}_{\mathrm{mL}}^{-1}$ enquanto que as com ordenha manual apresentaram valores inferiores, entre 230 e 430 NMP.mL ${ }^{-1}$. Todavia, é evidente a necessidade do uso de boas práticas em todo o processo de ordenhar os animais. Esses resultados obtidos, servem para mostrar que produtores devem fazer uso de boas condições higiênicas, tanto na mecanizada quanto na manual, contribuindo para reduzir a contaminação do leite.

Dentre os fatores que mais contribuem para a ocorrência de microrganismos patogênicos no leite cru refrigerado, está o tipo de ordenha, a realização ou não do pré e pós-dipping, a maneira como é feita a secagem dos tetos das vacas e as instalações da sala de ordenha (PICOLI et al., 2014).

No presente trabalho, os resultados de todas as amostras coletadas, encontraram-se dentro do padrão estabelecido pela legislação brasileira de acordo com a Instrução Normativa no 62/2011, ou seja, todas apresentaram valores de CBT abaixo de $1,0 \times 10^{5}$ UFC. $\mathrm{mL}^{-1}$ (Tabela 4), que indica boas condições de higiene da ordenha e dos equipamentos (FR, 2018).

TABELA 4- Contagem bacteriana total das amostras de leite cru refrigerado das propriedades analisadas, no decorrer das semanas de coleta.

\begin{tabular}{cccccc}
\hline \multirow{2}{*}{ Coleta } & \multicolumn{5}{c}{ Contagem Bacteriana Total (CBT) (UFC. $\mathbf{m L}^{-1}$ ) } \\
\cline { 2 - 6 } & $\mathbf{P 1}$ & $\mathbf{P 2}$ & $\mathbf{P 3}$ & $\mathbf{P 4}$ & $\mathbf{P 5}$ \\
\cline { 2 - 6 } 1 & $1,0 \times 10^{4}$ & $7,0 \times 10^{3}$ & $10,3 \times 10^{3}$ & $9,7 \times 10^{3}$ & $6,0 \times 10^{3}$ \\
2 & $1,3 \times 10^{4}$ & $6,6 \times 10^{3}$ & $5,5 \times 10^{3}$ & $9,0 \times 10^{3}$ & $5,2 \times 10^{3}$ \\
3 & $6,5 \times 10^{3}$ & $3,8 \times 10^{3}$ & $5,0 \times 10^{3}$ & $8,0 \times 10^{3}$ & $3,5 \times 10^{3}$ \\
4 & $6,0 \times 10^{3}$ & $2,0 \times 10^{3}$ & $3,4 \times 10^{3}$ & $7,1 \times 10^{3}$ & $1,2 \times 10^{3}$ \\
\hline Padrão & \multicolumn{5}{c}{$1,0 \times 10^{5}$} \\
\hline
\end{tabular}


Enquanto que na pesquisa desenvolvida por Sovinski et al. (2014), a média de CBT foi superior, com valor de 3,3 $\times 10^{8} \mathrm{UFC} \cdot \mathrm{mL}^{-1}$, refletindo condições higiênicas péssimas de ordenha, o que pode ocasionar queda no rendimento e redução de qualidade do leite e seus derivados. Valores inferiores à legislação vigente $\left(1,9 \times 10^{3}\right.$ UFC. $\mathrm{mL}^{-1}$ ), foram encontrados no Rio Grande do Sul por Silva et al. (2010b), quando compararam amostras leite cru refrigerado e pasteurizado comercializado.

\section{CONCLUSÕES}

O leite cru refrigerado produzido nas cinco propriedades leiteiras do município de Porto Acre, apresentaram teores médios de gordura, proteína e acidez em conformidade com os padrões estabelecidos pela legislação.

O leite analisado apresentou níveis de contaminação microbiológica abaixo do valor permitido pela legislação brasileira vigente e sendo assim, o leite das cinco propriedades avaliadas está adequado ao consumo humano.

Entretanto, se o leite cru refrigerado não for obtido de forma adequada, independentemente do nível tecnológico da propriedade, pode apresentar risco para a saúde humana, principalmente quando associado a condições insatisfatórias de armazenamento, transporte e sanidade animal.

\section{REFERÊNCIAS}

ALMEIDA, A. C. de; SANTOS, C. A. dos; MENEZES, I, R.; TEIXEIRA, L. M.; COSTA, J. P. R. et al. Perfil sanitário de unidades agrícolas familiares produtoras de leite cru e adequação à legislação vigente. Ciência Animal Brasileira, Goiânia, v. 17, n. 3, p. 303-315, jul./set. 2016. Disponível em: <https://www.revistas.ufg.br/vet/art icle/view/14597/21365>. doi: 10.1590/1089-6891v17i314597>.

BRASIL. Ministério da Agricultura, Pecuária e Abastecimento. Instrução Normativa no 62 de 29 de dezembro de 2011. Diário Oficial da União, Brasília, DF, seção 1, p. 6-11, 30 dez. 2011. Disponível em: < https://www.apcbrh.com.br/files/IN62.pdf>.

DIAS, J. A.; ANTES, F. G. Qualidade físico-química, higiênico-sanitária e composicional do leite cru. Porto Velho: Embrapa Rondônia, 2014. 24 p. (Documentos, 158). Disponível em: <https://ainfo.cnptia.embrapa.br/digital/bitstream /item/125963/1/Doc-158-leite.pdf>.

FAO. Food and Agriculture Organization. Milk production. 2017. Disponível em: <https: www.milkpoint.com.br/fao-producaomundialdeleites. Acesso em 20 novembro 2018.

FR. FUNDAÇÃO ROGE. Parâmetro de avaliação da qualidade do leite. 2018. Disponível em: <https://www.fundacaoroge.org.br/blog/3-par\%C3\%A2metros-deavalia\%C3\%A7\%C3\%A3o-da-qualidade-do-leite>. Acesso em 20 novembro 2018.

IAL. Instituto Adolfo Lutz. Normas Analíticas do Instituto Adolfo Lutz. Métodos químicos e físicos para análise de alimentos, 4. ed. São Paulo: IMESP, 2008. Disponível em: <http://www.ial.sp.gov.br/resources/editorinplace/ial/2016_3_19/anali sedealimentosial_2008.pdf $>$. 
JOSÉ NETO, N. A. O.; OLIVEIRA, E. N. A.; SANTOS, D. C.; SANTOS, Y. M. G.; ROCHA, A. P. T. Avaliação físico-química e possível ocorrência de fraudes em amostras de leite comercializadas informalmente em Encanto-RN. Revista Educação Agrícola Superior, Brasília, DF, v. 29, n. 2, p. 64-67, 2014. Disponível em: <https://www.researchgate.net/publication/280788374_AVALIACAO_FISICO-QUIMI CAE_POSSIVEL_OCORRENCIA_DE_FRAUDES_EM_AMOSTTRAS_DE_LEITE_COMERCI ALIZADAS_INFORMALMENTE_EM_ENCANTO-RN >. doi: 10.12722/0101-756X.v29n02a02

LAMAS, J. M. N.; MARTINS, M. L.; SILVA, F. J. M.; MARTINS, E. M. F.; BORGES, C. A. V. et al. Qualidade da água utilizada na limpeza dos tanques de granelização de leite cru: implantação e avaliação da cloração da água para garantia da qualidade do produto. Revista do Instituto de Laticínios Cândido Tostes, Juiz de Fora, v. 70, n. 5, p. 239-252, set./out. 2016. Disponível em: <https://www.revistadoilct. com.br/rilct/article /download/449/381 >. doi: 10.14295/2238-6416.v70i5.449

MARTINS, E. S.; LIMA, C. M. F. Qualidade microbiológica de leite cru refrigerado obtido de propriedades rurais do município de Frutal-MG: comparação das ordenhas mecânicas e manual. Revista Brasileira de Tecnologia Agroindustrial, Ponta Grossa, v. 7, n. 1, p. 955-964, dez. 2012. Disponível em: <https://periodicos.utfpr.edu.br/rbta /article/view/1043/951>. doi: 10.3895/S1981-36862013000100008.

MOURA, R. C. de; SOUSA, J. S.; FERREIRA, R. de C.; RIZZATTI, I. M. Análise físico-química e microbiológica do leite cru comercializado em Roraima. Boletim do Museu Integrado de Roraima, Roraima, v. 11, n. 2, p. 29-38, jul. 2017. Disponível em: <https://uerr.edu.br/bolmirr/wp-content/uploads/2017/07/BOLMIRR-v112Moura-et-al.pdf>.

NEPOMUCENO, G. L. Influência da nutrição em gado leiteiro na qualidade do leite. 2016. Disponível em: <https://3rlab.wordpress.com/2016/10/07/influencia-danutricao-em-gado-leiteiro-na-qualidade-do-leite/s. Acesso em 22 novembro 2018.

PAULA, P. F.; CARDOSO, C. E.; RANGEL, M. A. C. Análise físico-química do leite cru refrigerado proveniente das propriedades leiteiras da região Sul Fluminense. Revista Eletrônica Teccen, Vassouras, v. 3, n. 4, p. 7-18, out./dez. 2010. Disponível em: <http://editora.universidadedevassouras.edu.br/index.php/TECCEN/a rticle/view/257/205>. doi: https://doi.org/10.21727/teccen.v3i4.257.

PICOLI, T.; ZANI, J. L.; BANDEIRA, F. S.; ROLL, V. F. B.; RIBEIRO, M. E. R. et al. Manejo de ordenha como fator de risco na ocorrência de microrganismos em leite cru. Ciências Agrárias, Londrina, v. 35, n. 4, p. 2471-2480, maio, 2014. Disponível em: <https://www.redalyc.org/articulo.oa?id=445744143021 >. doi: 10.543 3/1679-0359.2014v35n4Suplp2471.

ROCHA, K. L.; OLIVEIRA, A. P de; CARVALHO, J. W. P. Avaliação da qualidade do leite "in natura", pasteurizado e esterilizado, comercializado em barra do Bugres-MT. Enciclopédia Biosfera, Goiânia, v. 13, n. 23, p. 144, jun. 2016. Disponível em: < 
http://www.conhecer.org.br/enciclop/2016a/agrarias/avaliacao\%20da\%20qualidade\% 20do\%20leite.pdf>.doi: 10.18677/Enciclopedia_Biosfera_2016_010.

SANTOS, P. A.; SILVA, M. A. P.; ANASTÁCIO, P. I. B.; SILVA JÚNIOR, L. C. da; ISEPON, J. dos $S$. et al. Avaliação do leite cru refrigerado produzido na região sudoeste do estado de Goiás estocado por diferentes períodos. Revista do Instituto de Laticínios Cândido Tostes, Juiz de Fora, v. 63, n. 364, p. 36-41, set/out. 2008. Disponível em: <https://www.revistadoilct.com.br/rilct/article/view/62>.

SILVA, M. A. P.; SANTOS, P. A. dos; SILVA, J. W.; LEÃO, K. M.; OLIVEIRA, A. N. et al. Variação da qualidade do leite cru refrigerado em função do período do ano e do tipo de ordenha. Revista do Instituto Adolfo Lutz, Goiânia, v. 69, n. 1, p.112-118, mar. 2010a. Disponível em: <http://periodicos.ses.sp.bvs.br/pdf/rial/v69n1/v69n1a16.pdf>.

SILVA, V. A. de M.; RIVAS, P. M.; ZANELA, M. B.; PINTO, A. T.; RIBEIRO, M. E. R. et al. Avaliação da qualidade físico-química e microbiológica do leite cru, do leite pasteurizado tipo A e de pontos de contaminação de uma Granja Leiteira no RS. Acta Scientiae Veterinariae, Porto Alegre, RS, v. 38, n. 1, p. 51-57, ago. $2010 \mathrm{~b}$. Disponível em: <https://lume.ufrgs.br/bitstream/handle/10183/24004/000739105.pdf? sequence $=1$ \&isAllowed $=y>$.

SILVA, N.; JUNQUEIRA, V. C. A.; SILVEIRA, N. F. A.; TANIWAKI, M. H.; SANTOS, R. F. S.; GOMES, R. A. R. Manual de métodos de análise microbiológica de alimentos e água. 5. Ed. São Paulo: Livraria Varela, 2017. 534 p.

SOUZA, L. V.; MELONI, V. A. da S.; BATISTA, C de S.; MARTINS, M. L.; PINTO, C. M. F. et al. Avaliação da qualidade microbiológica e físico-química de leite UHT integral processado em indústrias do estado de Minas Gerais, Brasil. Revista Brasileira de Agropecuária Sustentável, Viçosa, MG, v. 4, n. 2, p. 6-15, dez. 2014. Disponível em: <https://periodicos.ufv.br/ojs/rbas/article/viewFile/2841/1324>. doi: https://doi.org/10.21206/rbas.v4i2.253.

SOVINSKI, A. I.; CANO, F. G.; RAYMUNDO, N. K. L.; BARCELLOS, V. C.; BERSOT, L. $\mathrm{S}$. Situação da comercialização do leite cru informal e avaliação microbiológica e físicoquímica no município de Cafelândia, Paraná, Brasil. Arquivos de Ciências Veterinárias e Zoologia da UNIPAR, Umuarama, v. 17, n. 3, p. 161-165, jul./set. 2014. Disponível em: <http://www.revistas.unipar.br/index.php/veterinaria/article/view/4938/2877>. doi: https://doi.org/10.25110/arqvet.v17i3.2014.4938. 